\title{
"humanidades
}

Revista Humanidades

ISSN: 2215-3934

humanidades@ucr.ac.cr

Universidad de Costa Rica

Costa Rica

\section{Las nueve sinfonías de Beethoven, Marta Vela: una nueva visión simbólica}

\section{Gisbert, Dra. Vicenta}

Las nueve sinfonías de Beethoven, Marta Vela: una nueva visión simbólica

Revista Humanidades, vol. 11, núm. 1, 2021

Universidad de Costa Rica, Costa Rica

Disponible en: http://www.redalyc.org/articulo.oa?id=498064330008

DOI: https://doi.org/10.15517/h.vllil.45061

\section{(c) (1) $\Theta \odot$}

Esta obra está bajo una Licencia Creative Commons Atribución-NoComercial-SinDerivar 3.0 Internacional. 


\section{Las nueve sinfonías de Beethoven, Marta Vela: una nueva visión simbólica}

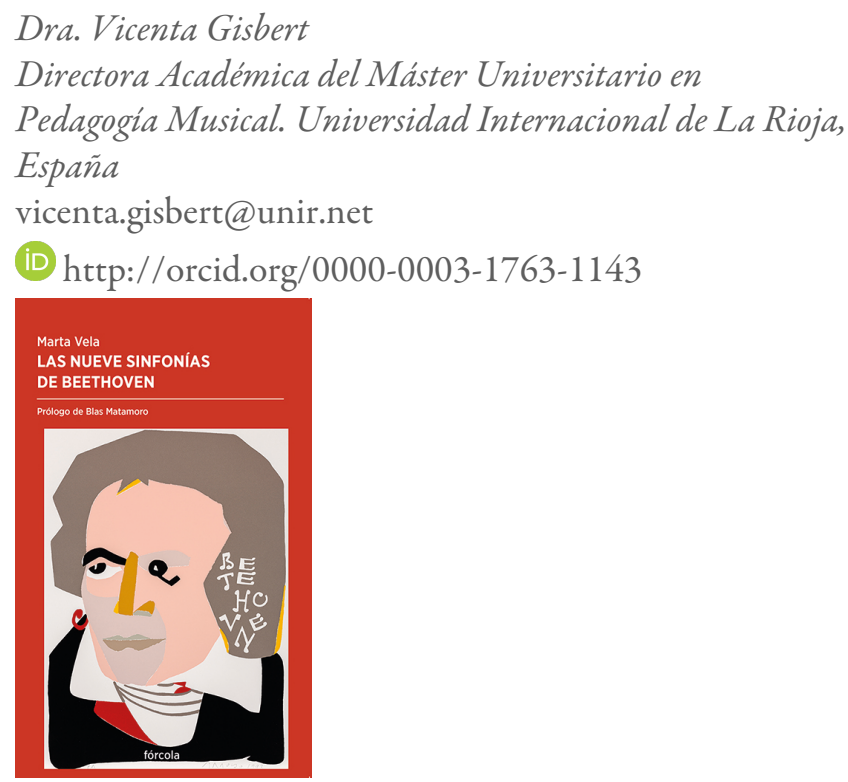

DOI: https://doi.org/10.15517/h.vllil.45061 Redalyc: http://www.redalyc.org/articulo.oa? $\mathrm{id}=498064330008$
Vela González Marta. Las nueve sinfonías de Beethoven. 2020. Madrid. Fórcola Ediciones. 248pp.

En el año 2020, el mundo conmemora el 250 aniversario del nacimiento de Ludwig van Beethoven, sin embargo, este reconocimiento se ha opacado debido a la crisis sanitaria internacional. Frente a todas las publicaciones relacionadas con dicha celebración, el libro Las nueve sinfonías de Beethoven de la autora Marta Vela y en su mayoría de carácter únicamente biográfico, representa un enfoque casi inédito: primero, debido a la valiosa contribución dentro del campo de las reflexiones teóricas y críticas en torno a la obra cumbre del compositor: las Nueve Sinfonías; y en segundo lugar, por el novedoso tratamiento de la evolución instrumental de la época desde el conjunto orquestal:

La orquesta, uno de los más felices hallazgos culturales del ser humano -tal vez, junto al cuarteto de cuerda-conoció una de sus primeras épocas de esplendor en el período clasicista, tras una larga trayectoria instrumental desde el siglo XVI, gracias a su maridaje con la forma sonata y, por ende, con el género de la sinfonía (Vela, 2020, p. 13).

A partir de una idea de amplio espectro cultural, la autora añade al estudio biográfico ya presentado en otras publicaciones anteriores, ahonda en la relación de los distintos acontecimientos sociopolíticos de la época (principalmente el período de las guerras napoleónicas y la época Biedermeier tras el Congreso de Viena), todos ellos vinculados con la evolución del género sinfónico y, en particular, con el modo compositivo de Beethoven. El lector obtiene, entonces, una interesante perspectiva acerca de la transición de la orquesta barroca a la clasicista, por medio de interesantes láminas que muestran los cambios instrumentales experimentados a lo largo de casi un siglo. Además de ello, se aprecia el deseo que poseía Beethoven de superar los modelos de sus predecesores (Haydn y Mozart) con relación a la creación de un ciclo sinfónico sin par hasta el momento, empero, desde los mismos medios técnicos de los cuales se había dispuesto en la segunda mitad del siglo XVIII:

Observemos trabajar a Beethoven en su recóndita imaginación sinfónica, absolutamente interior a causa de la sordera, dolencia que abarcó casi todo el ciclo de las nueve sinfonías, a excepción de la Primera y algún fragmento de la Segunda, en los albores del año de 1802: las ideas germinaban en la mente del compositor durante un largo período de tiempo -años, 
décadas-, apuntadas con dejadez en libretas de esbozos o cuadernos de conversación hasta que, por fin, se decidía a anotarlas en papel con la instrumentación completa y la forma definitiva (Vela, 2020, p. 26).

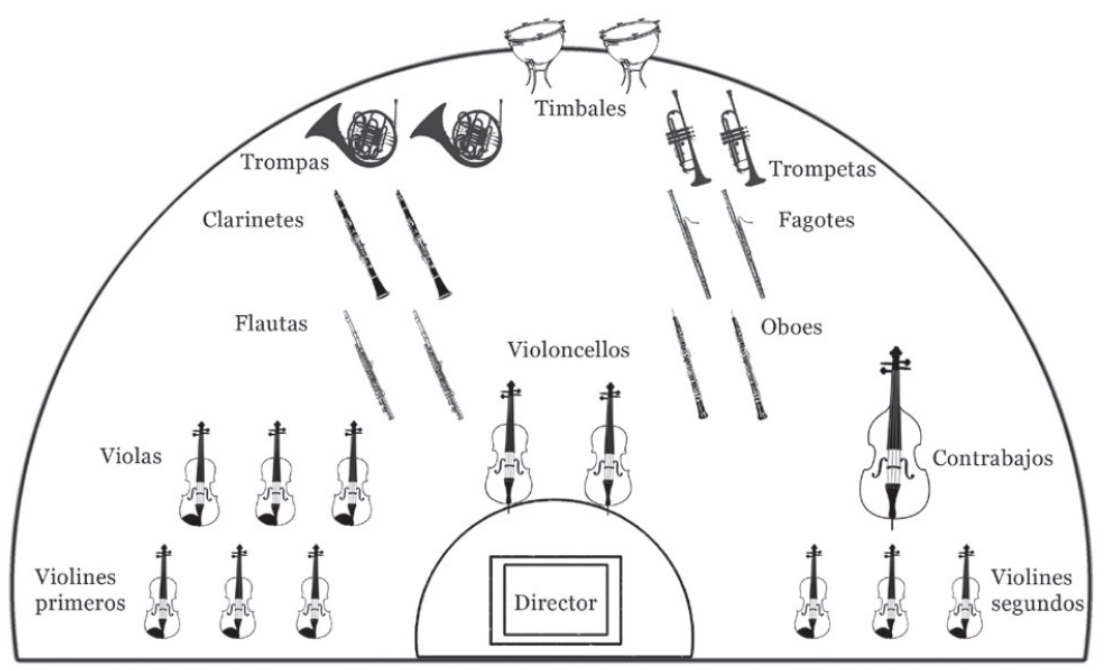

FIGURA 1

Plantilla orquestal de la orquesta de Mannheim en 1777

La tan comentada sordera del compositor, sobre todo, a la luz de la imaginería romántica, da pie a una nueva idea acerca de la magnitud sonora de la obra sinfónica de Beethoven que "rompió" el oído de sus contemporáneos. Lo anterior fue el motivo por el cual, en el contexto de la derrota definitiva de las tropas napoleónicas en los terrenos austro-alemanes, ninguna de estas obras (a excepción de la Séptima) triunfaría en su estreno, pese a su consideración actual:

Atesorando en su memoria distintos motivos sinfónicos durante largos años, hasta que tomaban forma por ellos mismos, Beethoven imaginaba para sí fabulosas obras sinfónicas, de dimensión armónica inaudita, jamás escuchada, tal vez, porque su sordera le impedía percibir la forma convencional de su época; al contrario, su inmarcesible fantasía le dictaba obras cada vez más voluminosas, en sentido sonoro, cuya puesta en escena final era incapaz de escuchar más allá de su mente, pese a que las dirigía en el estreno. De esta forma, ante la desgracia de su oído muerto, solo con el poder de su imaginación, Beethoven creó, por medio de una pasmosa economía de medios, cuanto nadie antes había logrado: una sorprendente expansión sonora surgida desde lo más profundo de su genio creador (Vela, 2020, p. 28).

Aunado a todo lo anterior, uno de los aspectos más relevantes del libro es la prueba de la "democratización" orquestal que Beethoven ejecutó en su obra sinfónica a raíz de su ideario ilustrado e igualitario, entroncado en las directrices de la Revolución francesa: "libertad, igualdad, fraternidad". De este modo, frente al predominio de la sección de cuerda durante la segunda mitad del siglo XVIII y buena parte del período barroco, Beethoven igualó -o se empeñó en realizarlo con las limitaciones técnicas de la época- las distintas familias instrumentales, en especial, las secciones de viento-madera y viento-metal a las cuales dotó de nuevas responsabilidades dentro del conjunto de la orquesta con el resultado de una potencia sonora nunca antes escuchada en la era clasicista.

Por lo tanto, Vela nos invita a abordar un camino poco transitado: el de la profundización en la obra musical a partir de un análisis simbólico que va desde el lenguaje orquestal de la época hasta lo más recóndito de la actividad creadora del compositor, encerrado en sí a causa de su sordera. La estructura del libro, simple, pero eficaz, comprende dos capítulos introductorios: I. Apuntes sobre la sinfonía clasicista y II. Beethoven y la sinfonía, los siguientes nueve capítulos, conciernen a cada una de las nueve sinfonías que se despliegan en dos partes: la primera, pormenoriza el contexto histórico de la obra con distintos testimonios de la época; la segunda parte, abarca el análisis orquestal del comienzo de cada una de las sinfonías y la interconexión entre 
ellas con jugosos símbolos escondidos en la partitura que habla de un Beethoven deseoso por imprimir su huella en la posteridad, a través de su discurso orquestal.

Además, la autora incluye un curioso bonus track, según su propia denominación sobre los vestigios de la Décima Sinfonía. Dichas reliquias fueron rescatadas de diversas bibliotecas europeas en forma de manuscrito, así como las circunstancias de la composición en los últimos días de la vida del compositor alemán, junto con una reflexión sobre la reconstrucción del musicólogo Barry Cooper en 1988.

Finalmente, el libro se cierra con el famoso lienzo de Danhauser, Liszt au piano (1840) como ejemplo de la pervivencia de Beethoven en el siglo XIX, paradigma de libertad, pero también de modernidad e independencia artística:

A pesar del manifiesto desorden de las partituras sobre la cola del piano, a los pies del busto ilustre -una exaltación romántica del poder de la música sobre el resto de las artes, solo se identifica aquella que reposa sobre el atril del piano, la que Liszt interpreta propiciando la admiración de sus invitados, la Marcia funebre sulla morte d'un Eroe -alegoría suprema de la pervivencia de Beethoven en un mundo futuro-, por un lado, ensayo previo de la Marcia funebre de la Heroica, por el otro, sello de despedida del compositor, cuya interpretación Stephan von Breuning encargó en los funerales de Beethoven, a los que el propio Danhauser había asistido muchos años antes, cuya honda impresión se mantuvo en el pintor hasta el final de su vida (1845) (Vela, 2020, p. 186).

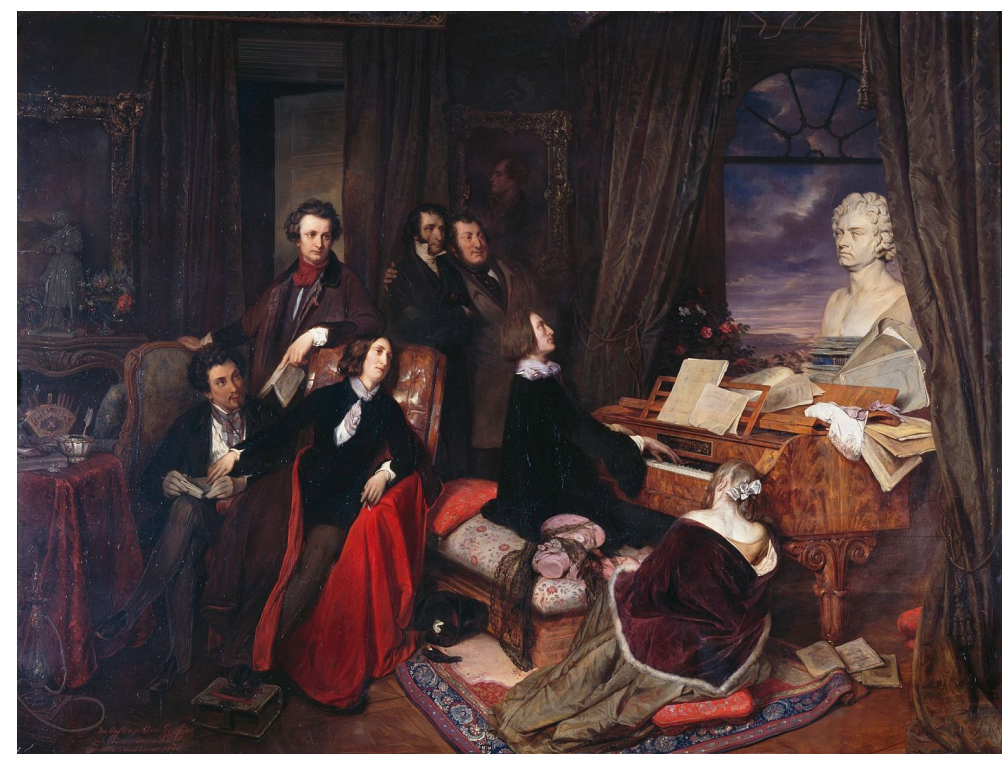

FIGURA 2

Danhauser, Liszt au piano (1840)

La enorme importancia de las nueve sinfonías de Beethoven dentro del conjunto de su obra bien merece el esfuerzo de su compresión profunda a través de diversos ejemplos musicales que refieren su enorme significación musical y artística:

Por este motivo, su música prevalecerá [la de Beethoven] y, como en el cuadro de Danhauser, brillará con luz propia hasta el fin de los tiempos, triunfando siempre sobre editores, intérpretes y cualquier tipo, en fin, de negociantes que de ella quisiesen aprovecharse más allá de su elevada posición como culmen del arte de los sonidos (Vela, 2020, p. 188).

Recomendable aporte dentro de la extensa bibliografía beethoveniana, sin duda, Las nueve sinfonías de Beethoven de Marta Vela ofrece una novedosa visión de la obra sinfónica del compositor alemán, más allá de lo puramente biográfico, de gran profundidad y con sutiles matices. Una publicación lejos de las habituales traducciones del alemán o del inglés, especialmente, por el hecho de haber sido elaborada en lengua española. 